\title{
Basic Strategies of Conflict Behaviour among the Region's Population
}

\author{
Victor V. Nagaitsev
}

\author{
Cand. Sci. (Soc.), Associate Professor, Head of the Department of Empirical Sociology \\ and Conflict Resolution Studies, Altai State University (Barnaul) \\ nvvv@yandex.ru
}

\begin{abstract}
The article analyses people's approach to conflict in the Altai Krai, one of the major regions of Siberia, and argues for the need for regional conflict management. The author presents data from empirical research conducted in the Altai Krai in 2016 within the project The Rating of Social Tension in Russian Regions during which 1,902 respondents were interviewed at their places of residence. The survey showed a high degree of civic illiteracy in the field of conflict resolution: the majority of the respondents were insufficiently informed about the methods of conflict resolution, and did not believe in the possibility of constructive conflict management. None of the respondents applied to the regional centres of mediation and conflict counselling, though about half of them reported feeling anger and hostility towards other people. One in five respondents was often confronted with conflicts and aggression outdoors and in public places. In addition, nine out of ten respondents were not able to identify the role and significance of the conflict in the society.

The article reassesses K. Thomas and R. Kilmeny's well-known classification of behavioural strategies in conflict from the standpoint of the modern conflict theory, and addresses the basic problems of modern conflict resolution studies in the context of the social conflicts concerning people of the region. The author carried out sociological analysis of conflict phobia in Russian society and investigates its main reasons, as well as solutions to the problem. The author formulates topical problems that must be addressed for the effective resolution of social conflicts in modern Russian society, including conflicts at the regional level.
\end{abstract}

The paper urges the development of methods for the management of regional society using controlled conflict.

Keywords: Social conflict, behaviour strategy in conflict, modern theory of conflict, diagnostic research methodology, conflict phobia, regional conflict management.

DOI: $10.21684 / 2587-8484-2017-1-1-62-68$

\section{THE PROBLEM}

In modern society, various social subjects interact more and more intensively than before almost in almost the all fields (e.g., representatives of large social groups, business partners, competitors, customers and suppliers of goods and services, work colleagues, friends, relatives, neighbours, etc.). Conflicts are one of the essential forms of social interaction. We define a social conflict as a process of confrontation, clash or another negative encounter between two or more
Citation: Nagaitsev V. V. 2017. "Basic Strategies of Conflict Behaviour among the Region's Population". Siberian Socium, vol. 1, no 1, pp. 62-68.

DOI: $10.21684 / 2587-8484-2017-1-1-62-68$

social actors caused by certain contradictions between their interests. Modern researchers view any conflict as a natural and inevitable phenomenon in all social systems, where it contributes to sustainable development and normal functioning [13: 35-39].

Conflicts can solve contradictions, strengthen mutual understanding and cooperation between social actors, improve group solidarity and reduce tensions. In some cases, however, social conflicts are the reason for opponents to concentrate all their 
attention on each other, to start interacting destructively, which threatens the very existence of the social actors. In this regard, the study of the basic behaviour strategies of the subjects in the emerging conflict response is of particular relevance. If conflict is an inevitable type of social interaction, and the contradictions of the goals and interests of social actors are ineradicable, the main focus area of social conflict is purposeful management. We believe that the most important aspect of this activity is conflict management at the regional level, where social conflicts are more violent.

\section{THE EMPIRICAL STUDY}

We performed sociological research in the Altai Krai in June-July 2016 within the framework of the project The Rating of Social Tension in Russian Regions. The results of the research show a high conflict level in this Siberian regional society.

Based on the official statistics of 1 January 2016, we calculated quotas by the respondents' place of residence, gender, age, and employment situation. According to the Russian Statistics Committee (Rosstat), the population of the Altai Krai comprises $2,376,774$ people (2016), of whom $46 \%$ are men and $54 \%$ women. $56.1 \%$ of this population is urban (2016). The Research Centre of the Sociology Faculty of Altai State University conducted a sociological poll of the urban and rural population between 27 June and 29 July 2016 in 10 settlements of the region (Barnaul, Biysk, Rubtsovsk, Aleysk, Topchikha, Pospelikha, Pavlovsk, Samarka, Bulanikha Romanova). The sample included 1,902 respondents, representing the population of $18 \mathrm{y} / \mathrm{o}$ and over, classified by sex, age, occupation and type of settlement. The quota, multi-stage and stratified sampling employed a step-by-step selection of the respondents and quotas in the selection's final stage. The margin of error (considering the effect of design) did not exceed $3.6 \%$. The survey was conducted in the form of personal standardised interviews at the respondents' places of residence.

The ratio of the respondents by gender: $46 \%$ male, $54 \%$ female. Average age: 35.8 y/o. Non-working pensioners: $13.4 \%$; pupils and students: $14.7 \%$; employees of commercial organisations: $19.9 \%$; workers in state-funded organisations: $23.0 \%$; civil servants: $8.2 \%$; private entrepreneurs and farmers: $3.6 \%$; unemployed: $3.8 \%$; agricultural labourers: $6.5 \%$; other areas of employment: $6.9 \%$.

The study shows that the population of the region is insufficiently informed on how to address emerging conflicts constructively. For example, $15 \%$ of the respondents went to court to find a way out of conflict; $28 \%$ tried to avoid conflict at all, and none of the respondents had applied to mediation and counselling centres; $68 \%$ of the respondents did not believe in the possibility of a constructive resolution to conflict; $89 \%$ of the respondents were not able to identify the role and importance of conflict in the community. Almost $1 / 5$ of the respondents said they had often faced conflicts and aggression in public places, and $1 / 4$ encountered such situations infrequently. Half of the respondents said they did not encounter conflicts and manifestations of aggression in general. In the most part, these people were villagers and people over $65 \mathrm{y} / \mathrm{o}$. $48 \%$ of the respondents disliked others, while $42 \%$ of the respondents had no such feelings.

Our research also shows that the population of the region is insufficiently informed on how to deal with emerging conflicts efficiently.

The analysis of the responses to the question "What words could you use to describe your mood lately?" shows that the majority of respondents reported a reasonable stable mood. Only $8 \%$ of respondents experienced stress and irritation. The majority of respondents (37\%) reported a stable mood, $18 \%$ were even in high spirits, and $4 \%$ experienced happiness. However, it is alarming that a relatively large group of the respondents $(15 \%)$ experienced indifference, apathy and hopelessness.

Answering the question "How have you adapted to modern market economic conditions?", the majority of the respondents $(43 \%)$ chose the answer "averagely", 17\% — "well", 18\% — "with difficulty", and one in ten said "did not adapt at all" or could not answer. In our opinion, this indicates that the population has adapted to modern market economic conditions.

The majority of the respondents $(62 \%)$ had no intention at all to protest against deterioration of their life quality. 
Despite the low overall verbal commitment to social protests, the data indicate high conflict intensity within the regional society of the Altai Krai, and the need to implement conflict management techniques.

\section{MODERN CONFLICT PHOBIA AND ITS THEORIES}

Conflict phobia prevents effective conflict management. We should recognise that

"today, the majority of people perceive a conflict as a very negative phenomenon and with great caution. $<$.. $>$ Modern researchers believe that conflict even has a quite unpleasant color, sound, smell and taste for human perception" [8: 76-77].

It is not surprising, therefore, that the fear of conflict is a common social phenomenon. Thus, conflict phobia is an individual's fear of being involved in conflicts with others and, consequently, their negative reaction to any conflict situation. The fear of conflict may be a result of the lack of contemporary philosophical, sociological, psychological and conflict knowledge; it is also related to national mentality. Russians are kind, patient, humble and gentle. On the other hand, they often demonstrate endurance, self-flagellation, resistance to change, reluctance to complete a task and a tendency to search for a culprit for their problems from the outside. Russian public opinion always interprets conflicts with frank dislike and fear, as something negative, indecent, ugly. The existing "groups of influence" present it as a form of deviant behaviour. Accordingly, the authorities condemn and prohibit new social movements seeking to change the existing state of society by means of launching conflicts and social protests.

60 years ago, the American sociologist L. Coser attempted to change the attitude of researchers to the phenomenon of social conflict. He proposed to consider conflict as a phenomenon which, apart from well-known negative functions, has a wide variety of positive facets for the social system. He described social conflict as "a dynamic type of interaction between social actors on the basis of certain contradictions in their aims and interests; it is constant and is not amenable to rapid elimination" [5: 28-40]. Thus, Coser put an end to the "long era of conflict phobia" in the social sciences which described conflict as a disease caused by the germs of deception, aggression and evil.

In Russia, the concept of conflict was highly politicised and ideologised (as has society as a whole) until the beginning of the 1990s. After many decades of so-called "conflict-free existence", demonstration and coercion are still the most common ways to resolve conflicts within society. Despite the problem of social contradictions being widely discussed in various fields of Russian academic literature, the discussion never broached the question of conflict's positive functions in Soviet society. Ideological clichés about "non-conflict Soviet society" affected people's minds, becoming a barrier to a positive understanding of conflict as one of the effective ways to overcome social contradictions.

The dichotomies of consent (consensus) and conflict, war and peace are central in many theories and schools. In the sphere of sociological knowledge there is a scientific approach conventionally called the "theory of consensus" or the "theory of stability" (as opposed to the "social conflict theory" by H. Spencer, K. Marx, G. Simmel, L. Coser, R. Dahrendorf, $\mathrm{K}$. Boulding et al.). The approach emphasises the following categories: "shared values", "stability", "balance", "sustainability" and "evolutionary development" of the social system. The vector in Western sociology conditionally named the "theory of consensus" (O. Comte, A. de Tocqueville, E. Durkheim, T. Parsons, R. Merton, N. Smelser, X. Brodal, D. Carnegie et al.), supporting the ideas of conflict phobia within society, can be found today in both international and Russian research $[11 ; 12 ; 17]$. Thus, the theory of stability does not contain explanations of conflict as a negative social phenomenon; it creates a basis for the development of ideas of conflict phobia.

In reality there are not only social conflicts, wars and revolutions, but also well-perceived human consensuses based on mutual human interests. Conflicts break the consensus, but resolving them recomposes it. Conflicts are of a temporary nature, while peace, harmony and prosperity among peoples are lasting. Sociology, conflict resolution studies, psychology and 
other social sciences exist for the sake of these eternal notions. It is worth noting that the concept of a conflict-free human society can be historically explained. Conflict phobia originates from the human nature: an individual needs to be safe, to have stable life, to form a stable social capital and maintain positive social relationships with other people. The breach of these expectations gives rise to feelings of anxiety and helplessness. A conflict is a real shock for the mind of an unprepared individual. Pre-existing or imminent conflicts threaten people and, thus, require them to mobilise all their resources. B. I. Hassan, one of the few Russian researchers in the field of conflict phobia, wrote:

"The most important point in conflict analysis lies in the fact that any conflict, regardless of its content and phenomenal representation, forms itself as a process of confronting actions. The variety of actions in a conflict immediately necessitates a painful and difficult selection. Since only one action can be done at a time, a clear choice is required. A conflict is a choice; the choice is always a denial; the denial of oneself, even partially, is painful and frightening!" [10: 26-29].

"Life itself is a matter of choices which subsequently bear risks. Conflicts are inevitable. And if they are inevitable, there is no point in fearing them. We should learn to manage them, to meet the needs and protect the interests of all parties" [9: 63-75].

Conflict phobia is based on the stereotype that conflicts impede the normal process of society and the individual, that there are no conflicts in respectable companies, households or families, and a bad compromise is always better than a lawsuit. Therefore, people do not usually tend to complicate relations with other people, and cannot tolerate quarrels and conflicts. Negative attitudes towards conflict are intensified by socio-cultural factors. All types of social structures are directed towards solidarity, coherence and cohesion, which are the basis of their stability. Any community will always censure or even directly condemn bad relationships among people within it, interpersonal conflicts, loneliness, alienation, failed marriage, etc. Another very impor- tant reason for conflict phobia in Russian society is "poor awareness of the existing non-violent methods and resolution techniques of conflict management" [6: 107]. The discussion of the conflict phobia issues in Russian society is a complex scientific problem. In addressing it, we can discover many useful facts about modern society.

The concept of "the total conflict tendency in society" has not yet received the status of a generally recognised research category in conflict sociology. Most researchers either generally avoid this concept, or reduce its meaning to all the conflicts that have taken place in society over time. In this case the focus is on interpersonal, political, ethnic, household, or labour conflicts, which are comprehended as autonomous social processes. It is therefore important to study not only (and not so much) the specificity of social conflicts, their causes and varieties, but their interaction and interdependence. The conflict system of society is transformed into a common system of interdependent processes. Surely, if one desires to examine an overall conflict in a particular local society, one cannot avoid the analysis of its internal social conflicts.

All social conflicts, although they arise due to various reasons and in different contexts, are interconnected and intertwined in a single "tangle". In other words, there are no purely political, ethnic, economic or labour conflicts. There is "a certain general social conflict of subjects" which is a particular phenomenon of the social life of society, and which integrates all the conflicts of its members. Conflict is a natural state for any society, a condition of its functioning and development.

\section{CONFLICT MANAGEMENT STRATEGIES}

The problem of conflict management is pivotal for us, in the sense that it derives from the understanding of conflict as a healthy social phenomenon. Recognition of social conflict's "sanity" broadens and deepens the issue of its regulation (forecasting, prevention, management and resolution). The specialists do not aim to totally eliminate all conflict in society, but develop the positive effects of conflict and minimise the destructive ones. 
In the early 1970s, K. W. Thomas and R. H. Kilmann classified all behavioural strategies in a conflict situation [15: 2-6]. The combination of the two factors outlined by them results in five basic behaviour strategies in a conflict: rivalry, avoidance, adaptation, compromise and cooperation. Each of these strategies has its advantages and disadvantages, and may correspond to one particular conflict situation, yet can be totally inappropriate for others.

Graphically, they can be presented as the famous Thomas-Kilmann Conflict Mode Instrument, which shows the location of each of the five basic behavioural strategies in conflicts (Table 1). This mode instrument is widely used today in a variety of personnel training programs on conflict management [1; 14: 60-72].

Furthermore, it is proper to consider these behavioural strategies from the viewpoint of Modern Conflict Theory, drawing attention to their advantages and disadvantages.

1. Rivalry with an opponent (confrontation, onesided domination, clash, strife and competition)

The formula of behaviour in a conflict: "one participant is striving to win at all costs and to make the opponent lose".

The desired conflict outcome: "win/lose".

Rivalry is a kind of behaviour in a conflict when the subject seeks to satisfy only their own interests at the expense of the opponent. The strategy is aimed to eliminate or dominate the rival. Such a person will argue for their position and will not consider the opponent's point of view. The stubborn defense of one's interests can help the social actor to win temporarily in a conflict situation. However, this approach is not applicable to long-term relationships with other actors.

Competition or direct confrontation should only be considered in situations where the subject has enough resources, they are confident in the benefits

\begin{tabular}{l|c|c|c|}
\hline $\begin{array}{l}\text { Table 1. The five basic strategies of behaviour in a conflict } \\
\text { max }\end{array}$ & Rivalry & Cooperation \\
\hline $\begin{array}{c}\text { Focus on } \\
\text { self-interest }\end{array}$ & min & Avoidance & Compromise \\
\hline
\end{tabular}

of their position or decision, the subject has sufficient authority and power, there is an urgent need for a rapid response to the destructive actions of the opponent and, finally, there is no other way to act. Rivalry is often associated with the use of physical, administrative, financial and other forms of violence. From this point of view, this behaviour should be recognised as generally undesirable, though rivalry makes the actors more active.

2.Adaptation to the opponent's actions (patience; adaptation; expectation; deferred decision)

The formula of behaviour in a conflict: "wait for a decision"; "wait and see"; "do whatever you want - just let's live in harmony"; "The Lord is slow in anger and so we should be".

The desired conflict outcome: "lose/win".

Adaptation to the opponent's actions in a conflict is a kind of behaviour observed when the subject ignores the conflict itself or denies its existence; it is a type of self-deception. Responding in this way, one can settle ("freeze") a conflict temporarily, but not resolve it.

Adaptation can be quite acceptable in a conflict situation when:

- chances are high that everything will be over soon;

- there is a desire to make a gesture of goodwill;

- the opponent is in the right;

- the fundamental interests of the subject are not challenged;

- it is necessary to interact with the opponent in the future;

- a good relationship with another party is more important than the decision.

\section{Compromise (the give-and-take approach)}

The formula of behaviour in a conflict: "to win something, each party has to give something away way".

The concomitant losses of compromise are inevitable, although, initially, they are not perceived to be necessary or even possible. Generally, the parties divide the conflict object between themselves, and everybody's participation is necessary.

\section{Cooperation (partnership, mutually beneficial interaction)}

The formula of behaviour in a conflict: "serving the interests is more important than demands and positions". 
The desired conflict outcome: "win/win".

Cooperation implies serving the interests of each party in the conflict. Clearly, this strategy, like the above-mentioned, is not always acceptable or even possible, but in most conflict situations, it is the most reasonable.

Strange as it may appear, this strategy is used quite often in real life. Any system of stable social relations is not characterised by compromise, failure or patience, but by cooperation. If the interests of any party of the social interaction are not fully satisfied, it will begin to choose other partners. In other words, conflict can be very useful if it is aimed to build a more profitable partnership with people. The theory of repeated interactions, developed by R. J. Aumann, the Nobel Prize winner in Economics (2005) for his contributions to the understanding of the nature of conflict, formulated the "folk theorem" (this name was suggested by Aumann himself): "in long-term relationships, parties may refrain from actions that promise short-term gains" [2: 98].

\section{Avoidance of conflict with others}

The formula of behaviour in a conflict: "not to get involved."

The desired conflict outcome: "neither win nor fail".

Avoidance is a behavioural response in which one of the parties in the conflict ignores its opponent or evades them. There are conflict situations when it makes sense to use this strategy:

- there is no actual conflict (false conflict situation);

- there is a trifling reason for a conflict;

- a social subject does not have resources to participate in the conflict with the opponent (physical power, money, time, allies, weapons, etc.);

- the result of the conflict is unpredictable, or there is a high probability of a failure;

- the conflict is destructive and not desired by the subject.

It should be recognised that today, the majority of people perceive the concept of conflict negatively and with great caution. In such situations, it is quite natural for many people (except for fearless individuals or feisty debaters) to avoid conflict situations (i.e. to escape, to get away, to hide or to run away). It is not surprising, therefore, that the fear of conflict is a common phenomenon in human society. Thus, we can say that conflict phobia is an individual's fear of being involved in conflict with others and, consequenly, their negative reaction to any conflict situation. Fear in this case causes the subject to choose the avoidance strategy, i.e. a quick escape. Conflict phobia is neglecting problems with other people, a desire to conceal and ignore them. The fear of conflict, like any other phobia, is a disease. If an individual experiences a constant fear of conflict with other social actors, they will not be able to protect their own views and interests.

\section{RESEARCH PERSPECTIVES}

Upon closer examination of the essence of the problem, a new methodological approach becomes evident, i.e. another point of view that accepts conflict as a constructive social phenomenon, rather than a destructive one, as well as a source of changes and development in social relations. Conflict tendency is a normal state in any society, community or interpersonal relationship. People are afraid of instability; they fear taking risks and confronting others, forgetting the possible constructive effects of such risk. In Chinese, the word conflict is composed of two characters: one represents risk (danger, abyss), and the second, new opportunities. The Chinese believe that too much harmony is dangerous. Complete harmony in human relations is always illusory. There are very important factors of social interaction: "creative confrontation" and "constructive conflict" [7: 146]. Willingness to participate in a conflict, to head for confrontation, the ability to resolve arising conflicts constructively, and the desire to cooperate increase a person's self-esteem, making them more confident and stronger. Conflict phobia creates indifference, cowardice, self-doubt, intimidation, etc.

The problems of overcoming conflict phobia and developing a culture of peace and non-violent conflict management in Russian society are presented below:

1. Russian conflict resolution studies have not yet taken shape as an independent field. Russian conflict sociology, as well as the sociology of 
industry, is too young to qualify for the perfection of its theoretical-methodological and practical developments.

2. Are the theoretical and methodological models of developed Western conflict sociology applicable to the study of social conflicts in Russian society?

3. What is a sufficient motive for a social subject to participate in a conflict? Is it provoking an opponent, being provoked, possible consequences for the participants, or something else?

4. Is it possible to assume that social actors who behave aggressively in a conflict, e.g., at their workplace, behave as aggressively in their family?

5. What are the criteria of social importance of emerging conflicts? For example, should a demonstration of a hundred people shown on a news programme be recognised as a more important social action than the thousands of production and management conflicts which are not even registered?

\section{CONCLUSION}

Increasing the level of literacy in the field of conflict resolution is a way to overcome conflict phobia. The level and quality of conflict education in Russia leave much to be desired today. Not all Russian citizens are aware of this science. The regional centres of non-violent conflict management and conflict counselling, mediation and assistance in the negotiation process are the exception rather than the rule [4: 112].

All conflicts in society are interrelated: they prevent those that are more damaging to the society and control the less dangerous ones. Management of regional society by means of conflict is a noticeably undeveloped area of modern conflict sociology, and appears to be very promising at present.

\section{REFERENCES}

1. Atteya N. 2012. Conflict Management. Saarbrücken: Lambert Academic Publishing.

2. Aumann R. J., Maschler M. B. 1995. Repeated Games with Incomplete Information, Cambridge, Massachusetts.

3. Ayalew M. 2012. The Role of Regional Organisations in Conflict Transformation, p. 112. Saarbrücken: Lambert Academic Publishing.

4. Chumikov A. N. 1995. "Upravlenie konfliktom i konfliktnoe upravlenie kak novye paradigmy myshleniya i deystviya" [Conflict Management as a New Paradigm of Thinking and Action]. Sociologicheskie issledovaniay, no 3 , p. 52.

5. Coser L. A. 1956. The Functions of Social Conflict. Cambridge: Free Press.

6. Danakin I., Dyatchenko L. 1993. "Tehnologiya razresheniya socialnyh konfliktov" [Techniques for Resolving Social Conflicts]. Sociologicheskie issledovaniay, no 9, p. 107.

7. Gloria I. 2013. Conflict Analysis and Resolution, p. 146. Saarbrücken: Lambert Academic Publishing.

8. Karakoz E. I. 2006. Together, pp. 76-77. Koblec: Fyolbah.

9. Khasan B. I. 1990. "Paradoksy konfliktofobii” [Paradoxes of Conflict Phobia]. Filosofskaya i sociologicheskaya mysl, no 6, pp. 63-75.

10. Khasan B. I. 1996. "Priroda i mehanizmy konfliktofobii" [The Nature and Mechanisms of Conflict Phobia]. In: Psihotehnika konflikta i konfliktnaya kompetentnost, pp. 26-29. Krasnoyarsk: Fond mentalnogo zdorovya.

11. Kozyrev G. I. 2013. "Zhertva i konflikt: socialno-antropologicheskiy analiz" [The Victim and Conflict: Socio-Anthropological Analysis]. Sociologicheskie issledovaniay, no 12, pp. 18-25.

12. Kuraeva T. 2006. "Umet obschatsya bez konfliktov" [To Be Able to Communicate without Conflicts]. Russkiy yazyk, no 6(510), pp. 11-15.

13. Russell J., Cohn R. 2013. Conflict Resolution Research. Saarbrücken: Lambert Academic Publishing.

14. Scott V. 2015. Workplace Conflict Resolution. Saarbrücken: Lambert Academic Publishing.

15. Thomas K. W., Kilmann R. H. 2010. TKI Profile \& Interpretive Report. Pat Sample. March 2, pp. 2-6.

16. Truevtseva S. S. 1994. "Traktovka konsensusa u O. Konta" [The Interpretation of Consensus by Comte]. Sociologicheskie issledovaniay, no 11, p. 139.

17. Wisenius K. 2010. Conflicts of Norms and Jurisdictions. Saarbrücken: Lambert Academic Publishing. 